Article

\title{
Fatty Acid Characteristics of Isochrysis galbana Lipids Extracted Using a Microwave-Assisted Method
}

\author{
Cherng-Yuan Lin * and Bo-Yu Lin \\ Department of Marine Engineering, National Taiwan Ocean University, Keelung 202, Taiwan; \\ E-Mail: M9866017@ntou.edu.tw \\ * Author to whom correspondence should be addressed; E-Mail: Lin7108@ntou.edu.tw; \\ Tel./Fax: +886-2-2462-2307.
}

Academic Editor: Paul L. Chen

Received: 14 November 2014 / Accepted: 22 January 2015 / Published: 3 February 2015

\begin{abstract}
Lipids were extracted from Isochrysis galbana using a microwave-assisted method accompanied by various types of organic solvents. The effects of organic solvent type and microwave input energy on the fatty acid characteristics of the extracted lipids and their biodiesel product were investigated. Variations in the characteristics of the lipids extracted using a combination of $n$-hexane and iso-propanol solvents in both emulsion and direct mixtures were also compared. The experimental results showed that greater quantities of Isochrysis galbana lipids, and fatty acid methyl esters transesterified from those lipids, were extracted when using microwave irradiation with an organic solvent mixture of $n$-hexane and isopropanol in a 2:1 volumetric ratio than when using either $n$-hexane or isopropanol as the sole solvent. A greater quantity of Isochrysis galbana lipids was extracted when an emulsion of isopropanol solvent evenly dispersed in the continuous phase of $n$-hexane solvent was used than when a direct mixture of the two solvents was used. In addition, the quantity of lipids extracted from the dried Isochrysis galbana powder with the assistance of microwave irradiation was $9.08 \mathrm{wt} \%$ greater than when using traditional Soxhlet extraction without microwave irradiation.
\end{abstract}

Keywords: microwave-assisted extraction; Isochrysis galbana; microalgae lipid; solvent emulsion; fatty acid characteristics 


\section{Introduction}

Vegetable oils and animal fats, which have been used as human food for thousands of years, are now frequently used as feedstocks for manufacturing first-generation biodiesel. Transesterification reactions, catalyzed by heterogeneous or homogeneous catalysts such as $\mathrm{CH}_{3} \mathrm{ONa}, \mathrm{KOH}$ and $\mathrm{NaOH}$ are generally applied to convert the feedstocks into biodiesel. Although homogeneous strong alkaline catalysts are most often used in biodiesel production, the application of various heterogeneous solid catalysts is fast developing to overcome the shortcomings of homogeneous catalysts [1]. For example, the $\mathrm{Li}_{2} \mathrm{SiO}_{3}$ catalyst prepared from rice husk ash silica and lithium orthosilicate $\left(\mathrm{Li}_{4} \mathrm{SiO}_{4}\right)$ was used to successfully enhance biodiesel conversion rates $[2,3]$. This rapidly developing industry requires a great deal of arable land to grow sufficient vegetable oil for biodiesel production. The controversial issue of competition between food and fuel production in the use of land thus arises, as does the potential for environmental damage as rainforest and other natural habitats are replaced by bioenergy crops [4]. A new-generation biodiesel that uses non-edible architectural or agricultural waste is regarded as the solution to this problem. Some fast-growing algae strains that have high lipid contents and can be grown in a wide range of circumstances have been identified as an excellent alternative feedstock for biofuel [5].

The biomass of microalgae, including carbohydrates, proteins and lipids, is generally formed through the photosynthetic reaction of carbon dioxide in atmospheric air [6]. The amount of lipid production for a given growing area of algae can be as high as seven to 31 times that of terrestrial plants such as palm oil and canola oil [7]. Algae are recognized as having the highest photosynthetic lipid-production efficiency of any organism in the world [8].

The processes of harvesting microalgae and extracting their lipids are considered as key areas for reducing the production costs of biodiesel [9]. It has been hypothesized that if the microalgae cell walls could be broken, microalgae lipids could be effectively extracted using an organic solvent [10]. A few extraction methods have been developed, such as supercritical fluid extraction [11], Soxhlet extraction [12] and accelerated solvent extraction [13]. However, these traditional extraction methods not only require large amounts of chemical solvents, which can be detrimental to the environment and increase extraction costs, but are also very time and energy intensive [14]. Therefore, a microwave-assisted method was applied in this study to enhance the efficiency of extracting lipids from Isochrysis galbana by reducing the consumption of extracting solvents, time and energy.

Microwaves are a type of electromagnetic wave with a high frequency (between $200 \mathrm{MHz}$ and $300 \mathrm{GHz}$ ) that can pass through a medium into the interior of a sample. The molecules of a microorganism cell absorb this microwave energy so that the interior temperature and pressure of the cell increase. When the interior pressure of the microorganism exceeds the supporting capacity of the cell wall, the cell breaks and the interior lipids flow freely to mix with the surrounding absorbent [15]. Polar solvents such as water, ethanol and acetone are able to absorb microwave energy [16], so the extraction temperature should be lower than the boiling temperature of the solvent used. Each lipid has an ideal extraction temperature. The solvent used for extraction is also an important factor in determining the efficiency of the lipid extraction from the microalgae [17].

Potassium chloride is one of the compounds contained in seawater and has been used as a nutrient for culturing microalgae. When the microalgae powder is immersed in a solution of potassium chloride $(\mathrm{KCl})$, the $\mathrm{KCl}$ content gradually diffuses into the microalgae droplets and thus expands the droplet size. 
This causes the microalgae cell wall to become weaker and more susceptible to being broken by further microwave-assisted extraction force. A larger fraction of microalgae lipids can then be released and absorbed by an extracting solvent such as n-hexane. The immersion time and solution temperature could affect the extent of swelling of the droplets in the microalgae biomass. Hence, in this study, the effects of the temperature of the potassium chloride $(\mathrm{KCl})$ solution and immersion time on the microalgae mean sizes were investigated.

This study also compared four types of solvent: $n$-hexane, isopropanol, a direct mixture of these two solvents and an emulsion of the two solvents. These mixtures have superior lipid-solubility and microwave-absorbing capacities. After extraction, the characteristics of the extracted lipids and the fatty acid methyl esters produced from the Isochrysis galbana through transesterification were analyzed. The application potential of microwave irradiation combined with these organic solvents for microalgae extraction was also evaluated.

\section{Experimental Details}

Isochrysis galbana was provided by High-Trust Biotechnology Inc. (Hualien County, Taiwan). Walne's medium was used as the nutrition provider during microalgae cultivation [18]. This medium has four major components: a nutrient solution, a trace metal solution, a vitamin solution and a nitrogen source [8]. Surface seawater was sterilized using a high-pressure sterilizing cauldron (model TM-321, Hoyu Inc., Taipei City, Taiwan) at a temperature of $121^{\circ} \mathrm{C}$ and a pressure of $117.6 \mathrm{kPa}$ for 20 min before being used for culturing the Isochrysis galbana.

The cultivated microalgae were harvested when they reached a stable cultivation period. A centrifuge (Sorvall Legend Mach 1.6R model, Thermo Scientific Inc., Bremen, Germany) was used to separate the microalgae biomass from its aqueous medium. The separated microalgae biomass was then mixed with deionized water to wash the microalgae and remove impurities. The centrifuge was then used again to collect the clean microalgae biomass. A freeze dryer (Eyela FDU-1200 model, Tokyo Rikakikai Inc., Tokyo, Japan) was used to dry the microalgae biomass for 18 to $24 \mathrm{~h}$. The weight of the dry microalgae biomass was then measured.

To measure the variation in the mean sizes of the microalgae particles, the harvested microalgae biomasses were immersed in $0.54 \mathrm{M}$ potassium chloride $(\mathrm{KCl})$ solution at either $30{ }^{\circ} \mathrm{C}$ or $50{ }^{\circ} \mathrm{C}$ for 150 min. A charge couple device associated with an image analyzer (TK-C1380 model, JVC Inc., Yokohama, Japan) and Image-Pro Plus Version 4.1 analysis software were used to assess the mean variation in the droplet size of the microalgae. A spectrophotometer (Helios Beta Model, Thermo Fisher Inc., Waltham, MA, U.S.A.) was used to observe the variation in the optical density (OD) of the microalgae biomasses. A metallurgical microscope (BH2-UMA model, Olympus Inc., Tokyo, Japan) accompanied with a camera (C-35AD-4 model, Olympus Inc.) was used to examine and photograph the morphologies of microalgae cells after being irradiated by microwave.

Four solvents were used: $n$-hexane, isopropanol, a direct mixture of $n$-hexane and isopropanol and an emulsion of hexane and isopropanol. The emulsion mixture and direct mixture consisted of the same two solvents and volumetric proportions (2:1), but had a different solvent structure. To prepare the emulsion solvent, two immiscible phases were prepared, with one phase evenly dispersed in another continuous phase. This was achieved by adding a surfactant to reduce the surface tension between the 
two phases. After mixing $70 \mathrm{~g}$ of the solvent $n$-hexane with $0.1 \mathrm{~g}$ of lipophilic Span-Tween serial surfactant with a hydrophile-lipophile balance (HLB) equal to 7, another $30 \mathrm{~g}$ of isopropanol was fed into the beaker by a peristaltic pump and the mixture was stirred evenly using an electromagnetic agitator. This process produced an emulsion of many isopropanol droplets evenly dispersed in the continuous $n$-hexane phase. To form the direct mixture of the solvents, isopropanol and $n$-hexane were directly mixed in the same volumetric proportions as that of the emulsion solvent.

One gram of dry microalgae powder was mixed with each of the solvents described above. A microwave reactor (Tmo-17Mb model, Tatung Inc., Taipei City, Taiwan) at an input power of $0.26 \mathrm{~kW}$ associated with various solvents was used to break the microalgae cells so that the microalgae lipids could be exposed to the solvent mixture. The total microwave input energy was set to be in the range between $0 \mathrm{~J}$ and $8400 \mathrm{~J}$ by adjusting the irradiating time of the microwave reactor. After absorbing the microalgae lipids, the solvent mixture was vaporized away from the lipids using a nitrogen blow-down concentrator (HCG-12A model, Hoyu Inc., Taipei City, Taiwan). The quantity of microalgae lipid produced was obtained by calculating the weight ratio of the microalgae lipid to that of the dry microalgae powder prior to the lipid extraction process.

The lipid extracted by these organic solvents was further subjected to a transesterification reaction. Traditional two-step methods tend to produce fewer fatty acid methyl esters (FAME) from extracted lipids, so a method of direct lipid extraction and transesterification was carried out immediately after the microalgae powder was dried in the freeze dryer. After disruption by microwave irradiation the microalgae cells were treated with $8 \mathrm{~mL} \mathrm{KOH} / \mathrm{methanol}$. The mixture was heated and kept at $75^{\circ} \mathrm{C}$ for $20 \mathrm{~min}$ and then cooled to $25^{\circ} \mathrm{C}$. Then $8 \mathrm{~mL} 0.7 \mathrm{~N} \mathrm{HCl} / \mathrm{methanol}$ and $10 \mathrm{~mL} \mathrm{BF}_{3} /$ methanol were added to the mixture, heated to $75{ }^{\circ} \mathrm{C}$ for $15 \mathrm{~min}$ and then cooled to $25^{\circ} \mathrm{C}$. $n$-Hexane was thereafter used to extract the FAME [19]. This process has been shown to more efficiently produce FAME and thus increase the quantity of FAME. The quantity of FAME was obtained by calculating the weight ratio of FAME to the original dry microalgae powder weight. The data in the figures were obtained from the mean values of three repetitions in each condition.

\section{Results and Discussion}

\subsection{Effect of $\mathrm{KCl}$ Solution on Mean Microalgae Size}

The microalgae were harvested when they reached a stable growth period. The collected aqueous microalgae were centrifuged to separate water from the microalgae biomass. Figure 1 shows the mean variation in the microalgae droplet size between microalgae immersed in $0.54 \mathrm{M}$ potassium chloride (KCl) solution at $30^{\circ} \mathrm{C}$ and $50{ }^{\circ} \mathrm{C}$. After being immersed motionless for $150 \mathrm{~min}$, the mean droplet sizes of the microalgae were $1.949 \mu \mathrm{m}$ for those immersed at $30{ }^{\circ} \mathrm{C}$ and $2.361 \mu \mathrm{m}$ for those at $50{ }^{\circ} \mathrm{C}$. Given that the microalgae were immersed in potassium chloride solution, some of the solute substances may have been transmitted in or out via the cell membrane due to osmosis. Hence, a variation in the concentration of potassium chloride between the outer solution and the interior cell occurred. The extent of osmosis of potassium chloride into the interior cell of the microalgae was greater at higher solution temperatures, resulting in a swelling of the microalgae and larger microalgae mean droplet size (see Figure 1). The microalgae cell wall with larger mean droplet size tends to being broken more 
completely under further microwave irradiation so that greater quantity of microalgae lipid was released. This implies that higher immersion temperature could lead to a higher extent of the microalgae lipid extraction.

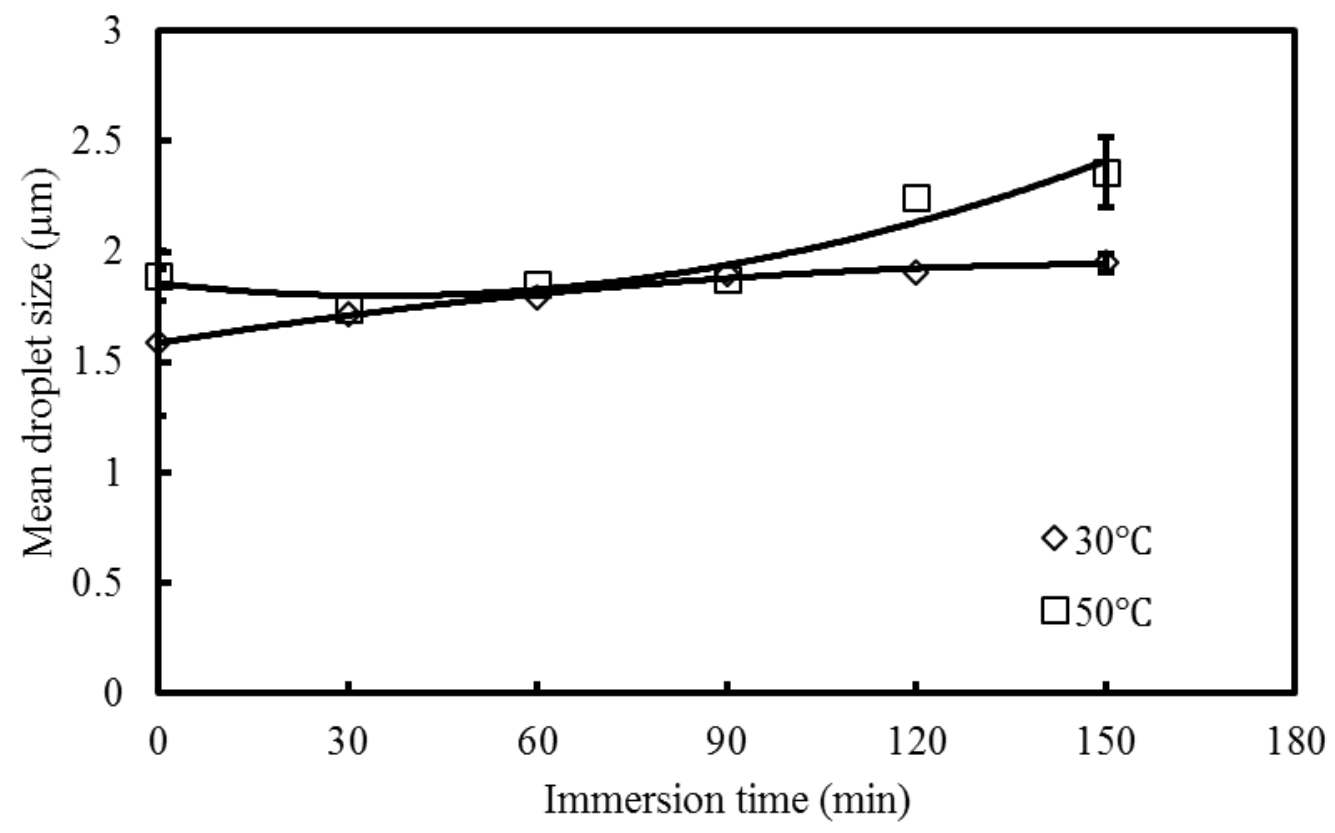

Figure 1. Variations in the mean droplet size in the microalgae biomass at different immersion times in a $0.54 \mathrm{M} \mathrm{KCl}$ solution at $30{ }^{\circ} \mathrm{C}$ and $50{ }^{\circ} \mathrm{C}$.

Variation was also observed in the microalgae optical density (OD) values of microalgae immersed at different temperatures. The OD value of the microalgae decreased from 1.69 to 1.57 and 1.63 to 1.39 after the solution was immersed at $30{ }^{\circ} \mathrm{C}$ and $50{ }^{\circ} \mathrm{C}$, respectively, for $150 \mathrm{~min}$ (see Figure 2).

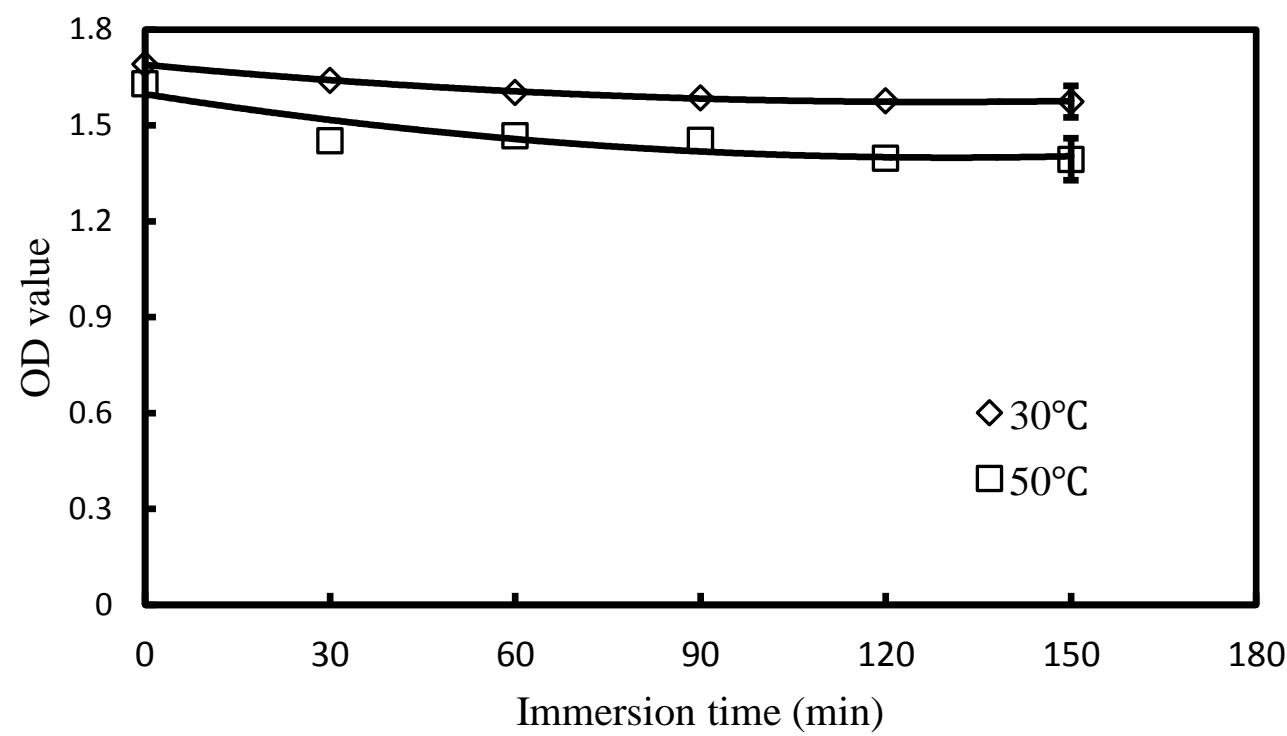

Figure 2. Variations in the optical density (OD) value of the microalgae biomass at different immersion times in a $0.54 \mathrm{M} \mathrm{KCl}$ solution at $30{ }^{\circ} \mathrm{C}$ and $50{ }^{\circ} \mathrm{C}$. 
The OD value of the microalgae biomass immersed in potassium chloride solution decreased with the immersion time and solution temperature. Hence, culturing temperature is one of the key factors for determining the microalgae growth rate. In general, the optimum culturing temperature for microalgae is between 15 and $30{ }^{\circ} \mathrm{C}$. The growth rate and lipid accumulation of microalgae may slow down when the temperature of their culturing environment exceeds $30^{\circ} \mathrm{C}$ [20]. This is accompanied by a decrease in the OD value, as shown in Figure 2.

\subsection{Effect of Extraction Solvent on Lipid Extraction}

After freeze drying, the lipid of the powder of Isochrysis galbana was extracted using the microwave-assisted method. Three solvents were used for lipid extraction: $n$-hexane, isopropanol and a direct mixture of $n$-hexane and isopropanol $(2 / 1 v / v)$. As shown in Figure 3, the highest amount of crude lipid (10.86 wt\%) was extracted from Isochrysis galbana when the solvent mixture of $n$-hexane/isopropanol $(2 / 1 \mathrm{v} / \mathrm{v})$ was combined with $6500 \mathrm{~J}$ of microwave energy.

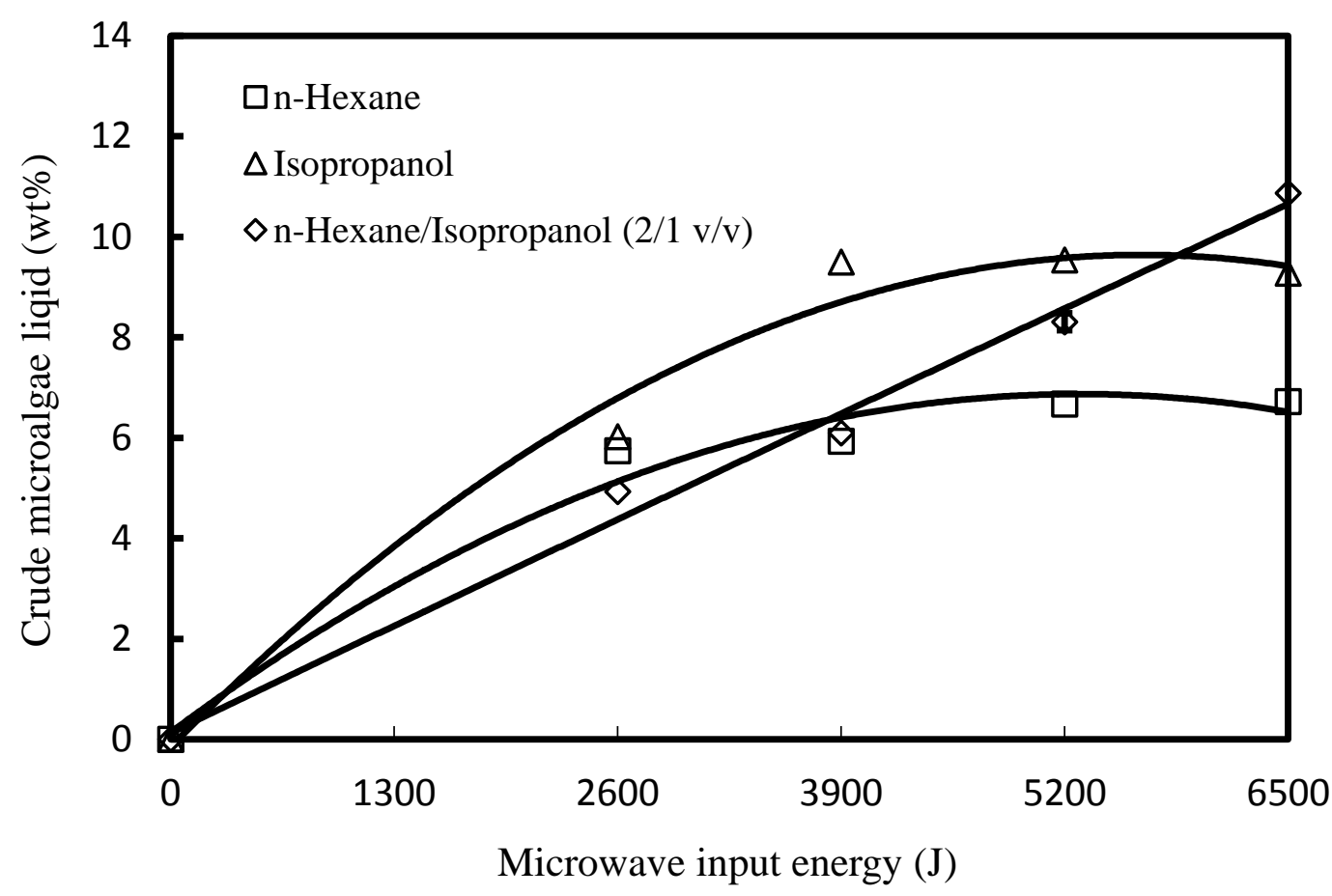

Figure 3. Effects of different organic solvents on the quantity of crude microalgae lipids extracted using the microwave-assisted method.

In addition, the crude microalgae lipid extracted by the solvent mixture was observed to be $42.2 \%$ higher in those lipids extracted by $n$-hexane and $14.5 \%$ higher in that extracted by isopropanol. The non-polar $n$-hexane solvent has excellent solubility in oil, whereas the polar isopropanol solvent has a superior capability for absorbing microwave energy [21]. Dai et al. [22] also found that the application of microwave fragmentation technology associated with adequate solvents can reduce both the extraction time of microalgae lipids and production cost of microalgae biodiesel. Together the $n$-hexane/isopropanol mixture $(2 / 1 v / v)$ has superior capabilities both for absorbing microwave energy and for extracting lipids. After absorbing the irradiated microwave energy, the aqueous solution of microalgae was gradually heated, which increased the interior pressure of the microalgae cells. 
The microalgae cells exploded once the formation of vapor increased the interior pressure to the point where it exceeded the supporting pressure of the cell wall. The cell morphologies of the microalgae which was irradiated by microwave at an input energy of $6500 \mathrm{~J}$ associated with a direct solvent mixture of $n$-hexane/isopropanol $(2 / 1 \mathrm{v} / \mathrm{v})$ can be clearly observed from the microscopic photograph at a magnification of $1000 \times$ in Figure 4. It is obviously that the microalgae cell walls were violently broken and torn outwards due to the effect of microwave irradiation. The microalgae lipids were therefore expelled through the broken cell walls and mixed with the solvent. A greater quantity of extracted lipids and a shorter extraction time were thus achieved when the mixed solvents of $n$-hexane and isopropanol were used with the microwave-assisted method.

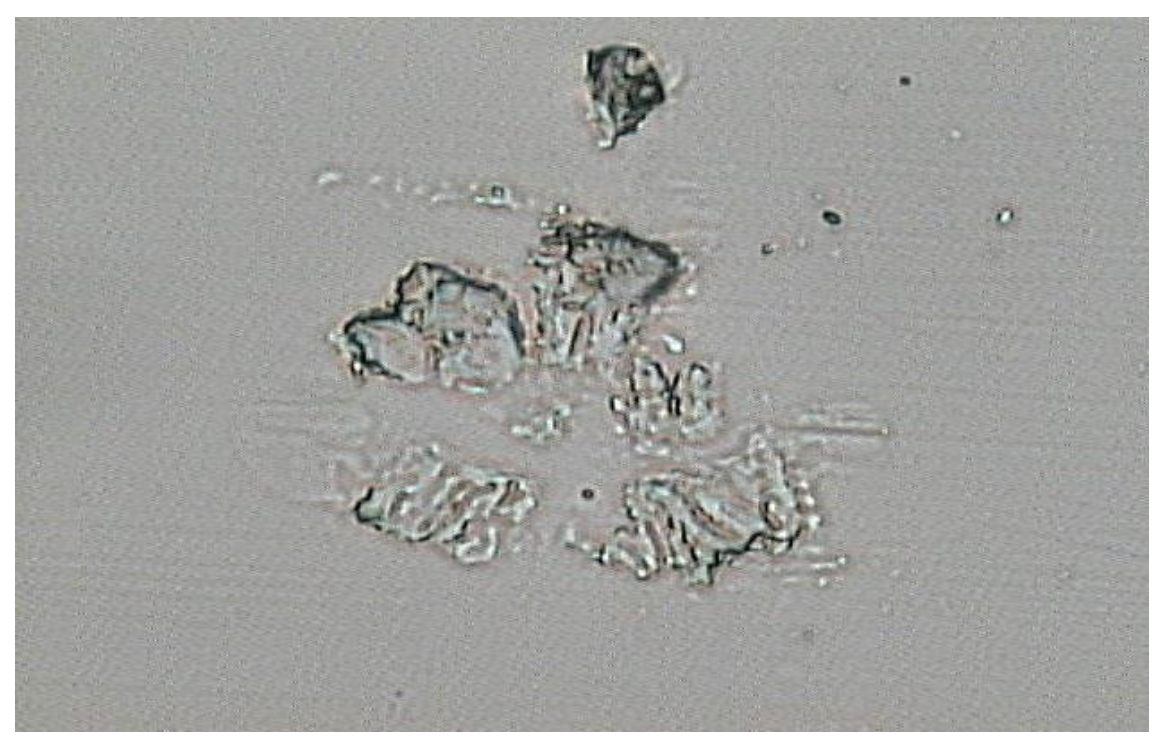

Figure 4. Microscopic photograph of the cell morphologies of the microalgae irradiated by microwave at an input energy of $6500 \mathrm{~J}$ associated with a direct solvent mixture of $n$-hexane/isopropanol $(2 / 1 v / v)$, at a magnification of $1000 \times$.

\subsection{Effects of Extracting Methods on Lipid Extraction}

The crude lipids of Isochrysis galbana that were extracted by microwave-assisted and Soxhlet extraction with the same $n$-hexane/isopropanol $(2 / 1 \quad v / v)$ direct mixture solvent were compared (Figure 5). The quantity of microalgae lipids was observed to be higher when the Soxhlet extraction method was used than when microwave irradiation with an input energy lower than $3150 \mathrm{~J}$ was used. However, the quantity of extracted crude Isochrysis galbana lipids increased as the input microwave energy increased. When $8125 \mathrm{~J}$ of microwave energy was applied, the quantity of extracted lipids reached $22.13 \mathrm{wt} \%$, which was $169.6 \%$ greater than that extracted by the Soxhlet method. This increase was probably due to the molecules in the microalgae cell walls colliding and rubbing against one another due to the irradiated microwave energy. The solvent was also susceptible to mixing with the crude lipids when the microwave-irradiating field was of high oscillating frequency. Thus, a greater quantity of Isochrysis galbana lipids was extracted by the microwave-assisted method. 


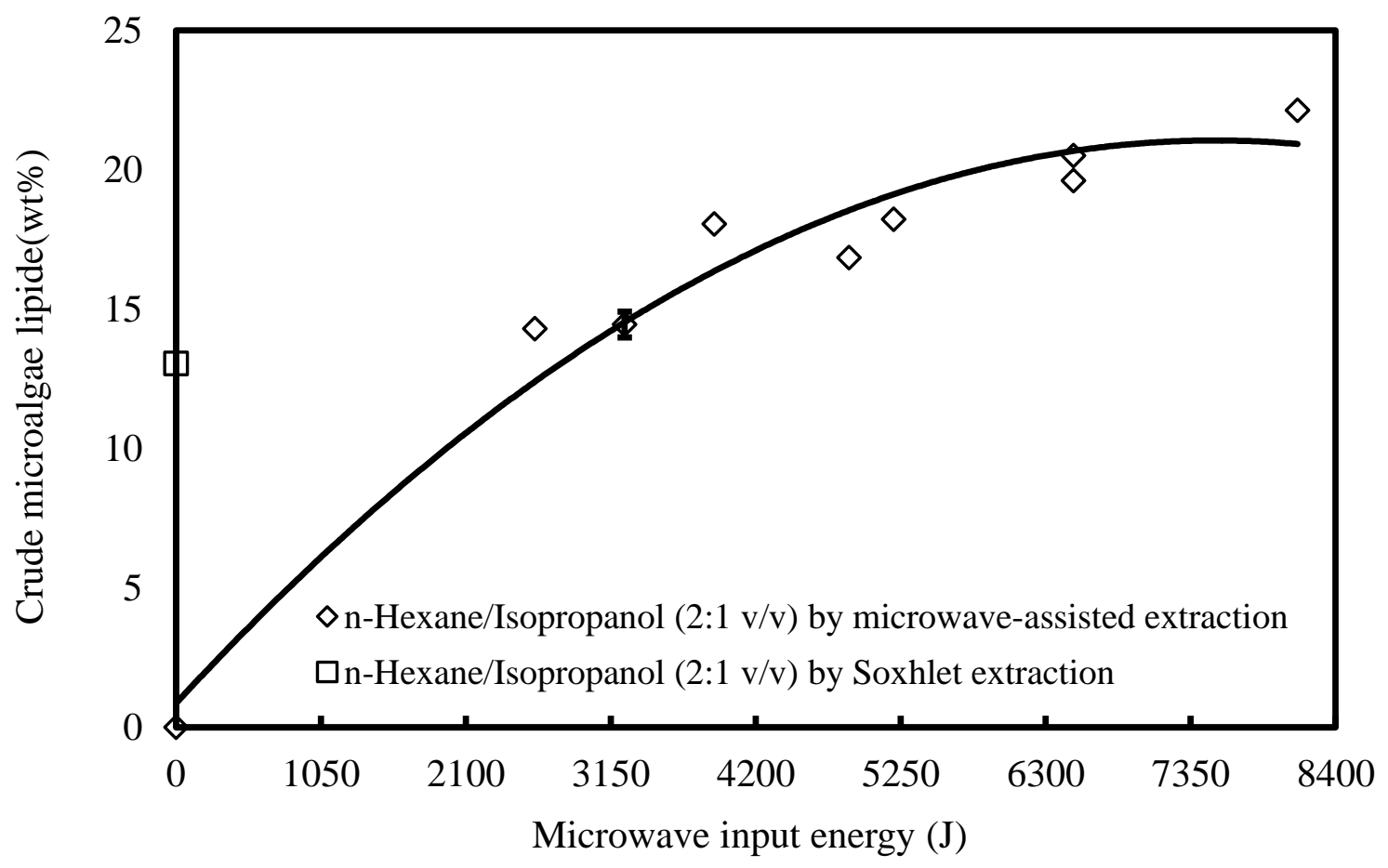

Figure 5. Comparison of the crude microalgae lipid quantities extracted using the Soxhlet and microwave-assisted extraction methods with an $n$-hexane and isopropanol solvent mixture under various input energies.

\subsection{Effects of Emulsion Solvent on Lipid Extraction}

The effects of the solvent structure on the lipid content of Isochrysis galbana extracted by the microwave-assisted method were also studied. Two solvent forms, an emulsion and a direct mixture of isopropanol and $n$-hexane, were prepared to observe the variation in extracted lipid content. The volumetric proportion of $n$-hexane and isopropanol in the emulsion and direct mixture was set at 2:1.

The quantities of Isochrysis galbana lipids extracted by the emulsion and the direct mixture increased with the increase in input microwave energy, as shown in Figure 6. The quantity of lipids extracted by the emulsion of isopropanol droplets dispersed in the continuous phase of $n$-hexane solvent was higher than that of the direct solvent mixture, except under input microwave energies higher than $5600 \mathrm{~J}$. In the direct solvent mixture, the amount of Isochrysis galbana extracted appeared to increase linearly with the increase in input microwave energy, and eventually began to exceed that of the emulsion solvent, as shown in Figure 6. This increase could be attributable to the fact that $n$-hexane is an oil-soluble, non-polar solvent that has a superior lipid extraction capability. In contrast, isopropanol, which is a polar solvent, is prone to absorbing microwave energy. The emulsion solvent consists of many dispersed isopropanol droplets enveloped in an outer, continuous $n$-hexane solvent. The evenly dispersed isopropanol droplets in the emulsion solvent can thus absorb the input microwave energy more efficiently, leading to faster break-up of the microalgae cells. The outer continuous $n$-hexane phase in the emulsion solvent could thus readily dissolve the outflowing lipid that was released from the broken microalgae cells under microwave irradiation. Hence, the emulsion solvent appeared to extract a higher microalgae lipid quantity than the direct solvent mixture. However, the emulsion structure is susceptible to being destroyed by high input microwave energies, resulting in an uneven solvent mixture of $n$-hexane 
and isopropanol. As a consequence, the quantity of Isochrysis galbana lipids extracted was lower than that of the direct solvent mixture under input microwave energies higher than $5600 \mathrm{~J}$, as shown in Figure 6.

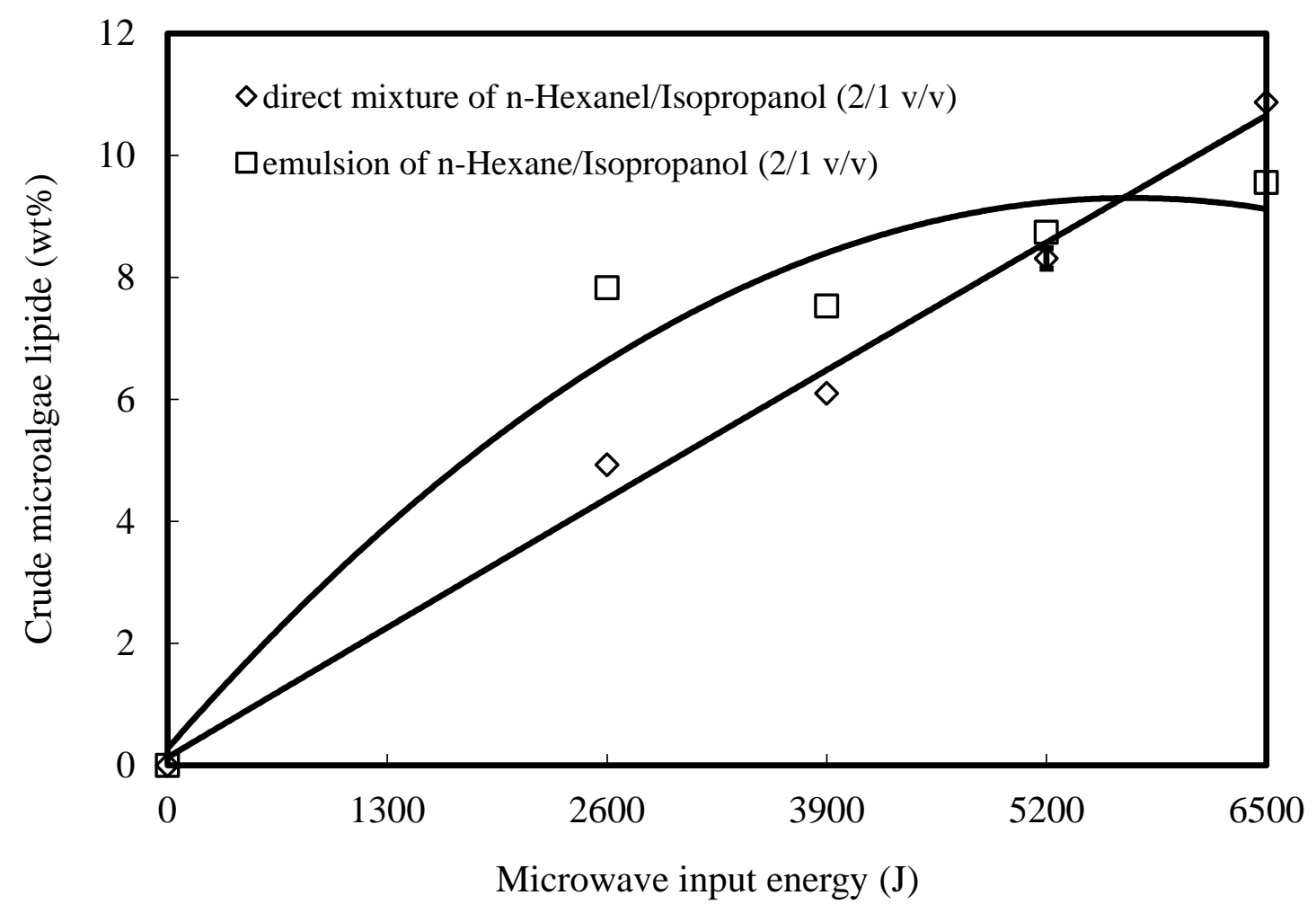

Figure 6. Comparison of the crude microalgae lipid quantities extracted by the microwave-assisted method with an emulsion solvent and a direct solvent mixture under various input energies.

\subsection{Effects of Extracting Solvents on Fatty Acid Methyl Esters}

The effects of extracting solvents on the quantity of FAME were also studied. The variation in the amount of FAME according to the type of solvent used is shown in Figure 7. The quantity of Isochrysis galbana FAME absorbed by the direct mixture solvent of $n$-hexane/isopropanol $(2: 1 \mathrm{v} / \mathrm{v})$ reached $77.4 \mathrm{wt} \%$. This was the highest quantity of FAME obtained from the various solvents, as shown in Figure 6. The same direct mixture solvent of $n$-hexane/isopropanol $(2 / 1 v / v)$ was shown to extract the highest quantity of crude Isochrysis galbana lipids when assisted with $6500 \mathrm{~J}$ of microwave input energy, as shown in Figure 3. This implies that a microwave-assisted extraction method for microalgae lipids can increase both the quantity of the crude extracted lipid and its FAME product when a direct solvent mixture of $n$-hexane and isopropanol is used, because microwave irradiation not only promotes the extent of the reaction among the molecules of activated compounds, but also alters the electrovalence of the molecular bonds and active ions [23]. The temperatures of the microalgae lipids and solvent would also have been increased by the microwave irradiation. It follows that both the quantities of the crude lipid and the corresponding FAME product of Isochrysis galbana increased as the input energy of the microwave irradiation increased. Microwave-assisted extraction with an $n$-hexane/isopropanol solvent mixture thus produced the highest quantity of crude lipid and FAME product of Isochrysis galbana, as shown in Figures 3 and 7. 


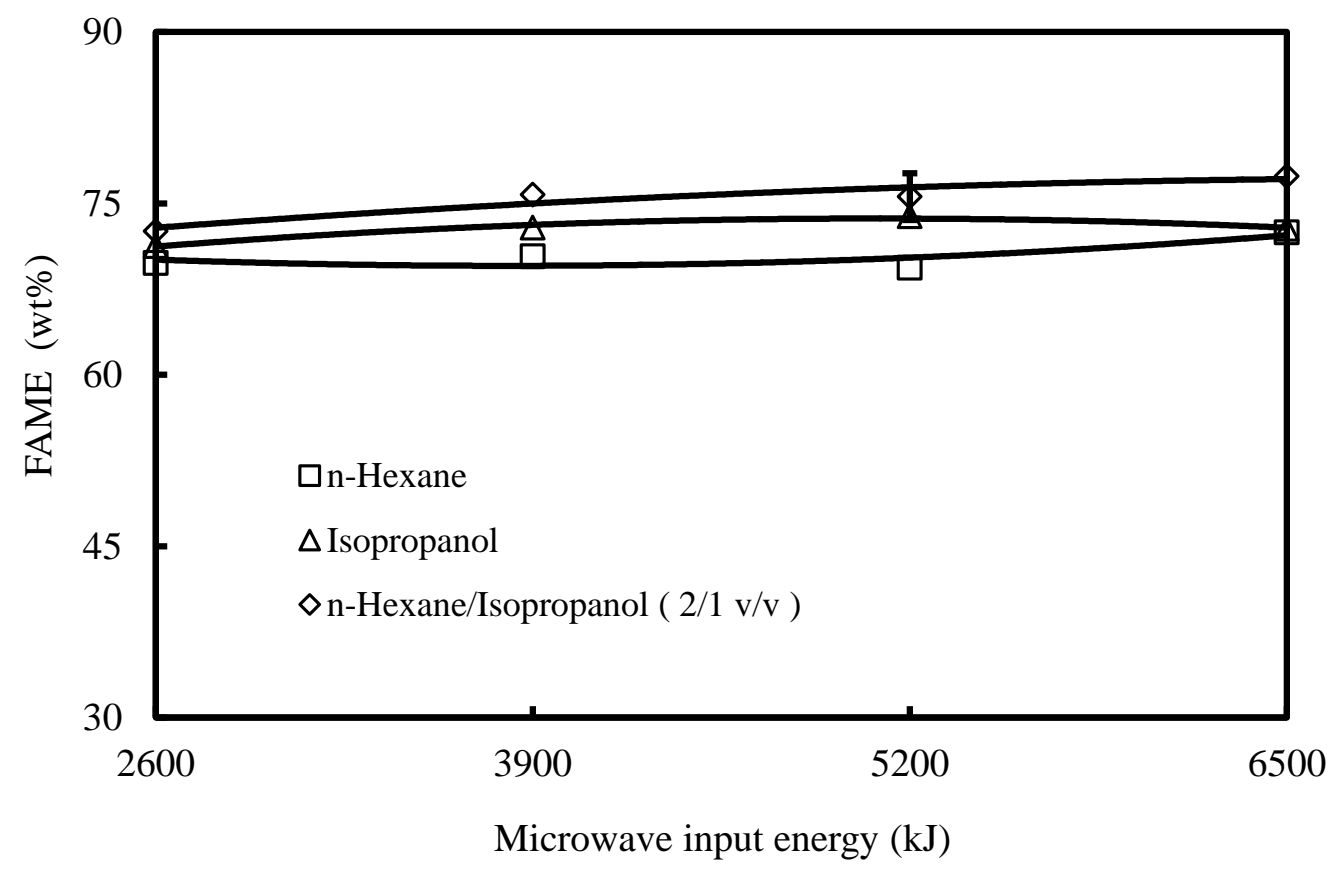

Figure 7. Comparison of the quantities of fatty acid methyl esters (FAME) extracted from the microalgae lipids using the microwave-assisted extraction method with various solvents.

\section{Conclusions}

A microwave-assisted method accompanied by various types of organic solvents was used to extract lipids from Isochrysis galbana. The microwave-assisted method was shown to have various advantages, including rapid and even heating, lower solvent consumption and shorter extraction time. It is also more environmentally friendly. The lipids and their FAME characteristics were analyzed in this study. The experimental results can be summarized as follows:

(1) The microalgae dry powder immersed in a potassium chloride solution of $0.54 \mathrm{M}$ at a higher temperature $\left(50{ }^{\circ} \mathrm{C}\right)$ was found to have a larger mean droplet size and lower OD values than those immersed at a lower temperature $\left(30^{\circ} \mathrm{C}\right)$. Higher temperature of a potassium chloride solution could be more effectively to expand and in turn break the microalgae cell for lipid extraction.

(2) The microwave-assisted method with an input microwave energy of $6500 \mathrm{~J}$ extracted a greater quantity of crude lipids from Isochrysis galbana when combined with a direct solvent mixture of $n$-hexane/isopropanol $(2 / 1 v / v)$ than when combined with either of these solvents alone. Moreover, the quantity of fatty acid methyl esters (FAME) extracted from Isochrysis galbana was higher when using the direct solvent mixture of $n$-hexane/isopropanol $(2 / 1 \mathrm{v} / \mathrm{v})$ compared to that of either $n$-hexane or isopropanol solvent used alone. Direct solvent mixture than either a solvent used alone has superior performance of lipid extraction and FAME production.

(3) The quantity of crude lipids extracted from Isochrysis galbana by the microwave-assisted method was significantly higher than that of the Soxhlet extraction method. Moreover, the quantity of crude Isochrysis galbana lipids increased with increased input microwave irradiation energy. The extracted lipids reached the maximum quantity of $22.13 \mathrm{wt} \%$ with $8125 \mathrm{~J}$ of microwave input energy. This was $9.08 \mathrm{wt} \%$ higher than the quantity extracted by the Soxhlet method. Microwave irradiation with higher input energy could extract more crude microalgae lipid. 
(4) In comparison with the direct solvent mixture of $n$-hexane/isopropanol (2/1 v/v), the emulsion of the same solvents with the same volumetric proportions was found to extract greater quantities of lipids from Isochrysis galbana when using the microwave-assisted extraction method, except at microwave input energies higher than $6500 \mathrm{~J}$. An emulsion rather than a direct mixture of combined solvents is more effective for crude lipid extraction from Isochrysis galbana particularly at lower microwave irradiation energies.

\section{Acknowledgments}

Financial support from the Ministry of Science and Technology, Taiwan, under Contract No: NSC-99-2221-E-019-029-MY3 is acknowledged.

\section{Author Contributions}

Professor Cherng-Yuan Lin is responsible for the implementation of the research project and contributes to the research idea and concept, experimental design and carry out, manuscript preparation, correspondence with the journal, reply to the comments, and other relevant issues regarding the experimental study and article publication. Bo-Yu Lin assisted in the experimental data acquisition and compilation.

\section{Conflicts of Interest}

The authors declare no conflict of interest to neither the contents nor the parties described in this manuscript.

\section{References}

1. Atadashi, I.M.; Aroua, M.K.; Abdul Aziz, A.R.; Sulaiman, N.M.N. The effects of catalysts in biodiesel production: A review. J. Ind. Eng. Chem. 2013, 19, 14-26.

2. Chen, K.T.; Wang, J.X.; Dai, Y.M.; Wang, P.H.; Liou, C.Y.; Nien, C.W.; Wu, J.S.; Chen, C.C. Rice husk ash as a catalyst precursor for biodiesel production. J Taiwan Inst. Chem. Eng. 2013, 44, 622-629.

3. Wang, J.X.; Chen, K.T.; Wu, J.S.; Wang, P.H.; Huang, S.T.; Chen, C.C. Production of biodiesel through transesterification of soybean oil using lithium orthosilicate solid catalyst. Fuel Process. Technol. 2012, 104, 167-173.

4. Yang, C.Y.; Fang, Z.; Li, B.; Long, Y.F. Review and prospects of Jatropha biodiesel industry in China. Renew. Sustain. Energy Rev. 2012, 16, 2178-2190.

5. Tanadul, O.; VanderGheynst, J.S.; Beckles, D.M.; Powell, A.L.T.; Labavitch, J.M. The impact of elevated $\mathrm{CO}_{2}$ concentration on the quality of algal starch as a potential biofuel feedstock. Biotechnol. Bioeng. 2014, 111, 1323-1331.

6. Sharma, K.K.; Schuhmann, H.; Schenk, P.M. High lipid induction in microalgae for biodiesel production. Energies 2012, 5, 1532-1553.

7. Demirbas, A.; Demirbas, F.M. Importance of algae oil as a source of biodiesel. Energy Convers. Manag. 2011, 51, 163-170. 
8. Lam, M.K.; Lee, K.T. Microalgae biofuels: A critical review of issues, problems and the way forward. Biotechnol. Adv. 2012, 30, 673-690.

9. Vandamme, D.; Foubert, I.; Muylaert, K. Flocculation as a low-cost method for harvesting microalgae for bulk biomass production. Trends Biotechnol. 2013, 31, 233-239.

10. Lee, J.Y.; Yoo, C.; Jun, S.Y.; Ahn, C.Y.; Oh, H.M. Comparison of several methods for effective lipid extraction from microalgae. Bioresour. Technol. 2010, 101, S75-S77.

11. Sahena, F.; Zaidul, I.S.M.; Jinap, S.; Karim, A.A.; Abbas, K.A.; Norulaini, N.A.N.; Omar, A.K.M. Application of supercritical $\mathrm{CO}_{2}$ in lipid extraction-A review. J Food Eng. 2009, 95, 240-253.

12. Wang, P.; Zhang, Q.; Wang, Y.; Li, X.; Ding, L.; Jiang, G. Evaluation of Soxhlet extraction, accelerated solvent extraction and microwave-assisted extraction for the determination of polychlorinated biphenyls and polybrominated diphenyl ethers in soil and fish samples. Anal. Chim. Acta 2010, 663, 43-48.

13. Rodríguez-Solana, R.; Salgado, J.M.; Dominguez, J.M.; Cortes-Dieguez, S. Characterization of fennel extracts and quantification of estragole: Optimization and comparison of accelerated solvent extraction and Soxhlet techniques. Ind. Crop Prod. 2014, 52, 528-536.

14. Pizarro, M.L.; Becerra, M.; Sayago, A.; Beltrán, M.; Beltrán, R. Comparison of different extraction methods to determine phenolic compounds in virgin olive oil. Food Anal. Methods 2013, 6, 123-132.

15. Lee, J.W.; Fukusaki, E.; Bamba, T. Application of supercritical fluid carbon dioxide to the extraction and analysis of lipids. Bioanalysis 2012, 4, 2413-2422.

16. Gude, V.G.; Patil, P.; Martinez-Guerra, E.; Deng, S.; Nirmalakhandan, N. Microwave energy potential for biodiesel production. Sustain. Chem. Process. 2013, 1, doi:10.1186/2043-7129-1-5.

17. Grima, E.M.; González, M.J.I.; Giménez, A.G. Solvent extraction for microalgae lipids. In Algae for Biofuels and Energy; Springer: The Netherlands, 2013; pp. 187-205.

18. Mata, T.M.; Martins, A.A.; Caetano, N.S. Microalgae for biodiesel production and other applications: A review. Renew. Sustain. Energy Rev. 2010, 14, 217-232.

19. Patil, P.D.; Gude, V.G.; Mannarswamy, A.; Cooke, P.; Nirmalakhandan, N.; Lammers, P.; Deng, S. Comparison of direct transesterification of algal biomass under supercritical methanol and microwave irradiation conditions. Fuel 2012, 97, 822-831.

20. Grossia, V.; Raphela, D.; Aubertb, C.; Rontania, J.F. The effect of growth temperature on the long-chain alkenes composition in the marine coccolithophorid Emiliania huxleyi. Phytochemistry 2000, 54, 393-399.

21. Terigar, B.G.; Balasubramanian, S.; Boldor, D. An analysis of the microwave dielectric properties of solvent-oil feedstock mixtures at 300-3000 MH. Bioresour. Technol. 2010, 101, 6510-6516.

22. Dai, Y.M.; Chen, K.T.; Chen, C.C. Study of the microwave lipid extraction from microalgae for biodiesel production. Chem. Eng. J. 2014, 250, 267-273.

23. Hernando, J.; Leton, P.; Matia, M.P.; Novella, J.L.; Alvarez-Builla, J. Microwave homogeneous batch and flow processes. Fuel 2007, 86, 1641-1644.

(C) 2015 by the authors; licensee MDPI, Basel, Switzerland. This article is an open access article distributed under the terms and conditions of the Creative Commons Attribution license (http://creativecommons.org/licenses/by/4.0/). 